\title{
ПОЛЯРИЗАЦИОННЫЙ ДОПЛЕРОВСКИЙ РАДИОСКАТТЕРОМЕТР Х-ДИАПАЗОНА ДЛЯ ИССЛЕДОВАНИЯ РАССЕЯНИЯ МИКРОВОЛНОВОГО ИЗЛУЧЕНИЯ НА ВЗВОЛНОВАННОЙ ПОВЕРХНОСТИ ВОДЫ В ЛАБОРАТОРНЫХ УСЛОВИЯХ
}

\author{
В. И. АБРАМОВ ${ }^{1}$, Э. М. ЗУЙКОВА ${ }^{2}$, Д. А. СЕРГЕЕВ ${ }^{2}$, Ю. И. ТРОИЦКАЯ ${ }^{2}$, \\ А. В. ЕРМОШКИН ${ }^{2}$ В. И. КАЗАКОВ ${ }^{2}$ \\ ${ }^{1}$ Федеральное государственное бюджетное научное учреждение \\ «Научно-исследовательский радиофизический институт», \\ Россия, Нижний Новгород, 603950, ул. Большая Печерская, 25/12a \\ ${ }^{2}$ Федеральное государственное бюджетное научное учреждение \\ «Федеральный исследовательский центр Институт прикладной физики Российской академии наук», \\ Россия, Нижний Новгород, 603950, БОКС-120, ул. Ульянова 46
}

\begin{abstract}
Аннотация. В работе описыан разработанный и изготовленный в ИПФ РАН экспериментальный образец доплеровского радиоскаттерометра непрерывного излучения (с синусоидальной частотной модуляцией) $\mathrm{X}$-диапазона, предназначенный для изучения физических процессов рассеяния радиоволн на морской поверхности в контролируемых лабораторных условиях. Основная его особенность заключается в адаптации к условиям лабораторного моделирования на ветро-волновых каналах с целью исследования зависимости удельной эффективной площади рассеяния от скорости ветра. Конструкция СВЧ части и антенной системы позволяет проводить измерения мощности рассеянного излучения, а также его доплеровского спектра, как на основных, так и на перекрестных линейных поляризациях в последовательном режиме переключения. Приведено подробное описание конструкции и технических характеристик. Также обсуждаются вопросы калибровки и приводятся полученные с его использованием результаты экспериментов на Высокоскоростном ветро-волновом канале ИПФ РАН.
\end{abstract}

Ключевые слова: доплеровский радиоскаттерометр, морская поверхность, перекрестная поляризация, лабораторный эксперимент

\section{ВВЕДЕНИЕ}

В настоящее время дистанционное зондирование Земли является одним из основных методов диагностики океана и атмосферы. Теоретические подходы к описанию и методы практического использования рассеяния микроволнового электромагнитного излучения при исследовании поверхности гидросферы изучались во многих работах [1-5].

Для измерения скорости и направления приводного ветра в оперативной практике широко применяются спутниковые радиолокационные устройства, прежде всего, скаттерометры (спутники MetOp, а до ноября 2009 и QuikSCAT). В отдельных регионах начато оперативное использование полей приводного

* Работа выполнена при поддержке проекта Российского научного фонда № 14-17-00667.

DOI: $10.20535 / \mathrm{S} 0021347017090023$

() В. И. Абрамов, Э. М. Зуйкова, Д. А. Сергеев, Ю. И. Троицкая, А. В. Ермошкин, В. И. Казаков, 2017 


\section{БИБЛИОГРАФИЧЕСКИЙ СПИСОК}

1. Юровский, Ю.Ю; Сергиевская, И.А.; Ермаков, С.А.; Шапрон, Б.; Капустин, И.А.; Шомина, О.В.Влияние обрушений ветровых волн на обратное рассеяние миллиметровых радиоволн морской поверхностью. Морской гидрофизический журнал, № 4, C. 37-50, 2015. URI: http://мгфж.pф/index.php/repo sitory? $\mathrm{id}=37$.

2. Кулемин, Г.П.; Разсказовский, В.Б. Рассеяние миллиметровых радиоволн поверхностью земли под мальми углами. К.: Наукова думка, 1987. 232 с.

3. Запевалов, А.С. Моделирование брегговского рассеяния электромагнитного излучения сантиметрового диапазона морской поверхностью. Влияние волн более длинных, чем брегговские составляющие. Известия РАН. Физика атмосферы и океана, Т. 45, № 2, C. 266-275, 2012. URI: https://elibrary.ru/item.asp?id= 11770187.

4. Караев, В. Ю.; Мешков, Е. М.; Чу, К. Особенности классификации типов волнения в задачах радиолокационного зондирования. Исследование Земли из космоса, № 4, С. 1-16, 2013. DOI: $10.7868 / \mathrm{S} 0205$ $\underline{961413040088 .}$.

5. Кравченко, В.Ф.; Луценко, В.И.; Луценко, И.В. Рассеяние радиоволн морем и обнаружение объектов на его фоне. М.: ФИЗМАТЛИТ, 2015. 448 с. ISBN 978-5-9221-1613-8.

6. Lehner, S.; Horstmann, J.; Koch, W.; Rosenthal, W. Mesoscale wind measurements using recalibrated ERS SAR images. J. Geophys. Res., Vol. 103, No. C4, P. 7847-7856, 1998. DOI: 10.1029/97JC02726.

7. Horstmann, J.; Schiller, H.; Schulz-Stellenfleth, J.; Lehner, S. Global wind speed retrieval from SAR. IEEE Trans. Geosci. Remote Sens., Vol. 41, No. 10, P. 2277-2286, 2003. DOI: 10.1109/TGRS.2003.814658.
8. Monaldo, F. M.; Thompson, D. R.; Beal, R. C.; Pichel, W. G.; Clemente-Colon, P. Comparison of SAR-derived wind speed with model predictions and ocean buoy measurements. IEEE Trans. Geosci. Remote Sens., Vol. 39, No. 12, P. 2587-2600, 2001. DOI: $10.1109 /$ 36.974994 .

9. Hwang, P. A.; Zhang, B.; Perrie, W. Depolarized radar return for breaking wave measurement and hurricane wind retrieval. Geophys. Res. Lett., Vol. 37, No. 1, P. L01604, 2010. DOI: 10.1029/2009GL041780.

10 . Hersbach, H. Comparison of C-band scatterometer CMOD5.N equivalent neural winds with ECMWF. $J$. Atmos. Oceanic Technol., Vol. 27, P. 721-736, 2010. DOI: 10.1175/2009JTECHO698.1.

11. Hersbach, H.; Stoffelen, A.; de Haan, S. An improved C-band scatterometer ocean geophysical model function: CMOD5. J. Geophys. Res., Vol. 112, No. C3, P. C03006, 2007. DOI: 10.1029/2006JC003743.

12. Hwang, P. A.; Zhang, B.; Toporkov, J. V.; Perrie, W. Comparison of composite Bragg theory and quad-polarization radar backscatter from RADARSAT-2: With applications to wave breaking and high wind retrieval. J. Geophys. Res., Vol. 115, No. C8, P. C08019, 2010. DOI: $10.1029 / 2009$ JC005995.

13. Zhang, B.; Perrie, W.; He, Y. Wind speed retrieval from RADARSAT-2 quad-polarization images using a new polarization ratio model. J. Geophys. Res., Vol. 116, No. C8, P. C08008, 2011. DOI: $\underline{10.1029 / 2010}$ JC006522.

14. Vachon, P. W.; Wolfe, J. C-band cross-polarization wind speed retrieval. IEEE Geosci. Remote Sens. Lett., Vol. 8, No. 3, P. 456-459, 2011. DOI: 10.1109/LGRS.2010.2085417.

15. Zhang, B.; Perrie, W. Cross-polarized synthetic aperture radar: A new potential measurement technique for hurricanes. Bull. Amer. Meteor. Soc., Vol. 93, P. 531-541, 2012. DOI: 10.1175/BAMS-D-11-00001.1.

16. Komarov, S.; Komarov, A.; Zabeline, V. Marine wind speed retrieval from RADARSAT-2 dual-polarization imagery. Can. J. Remote Sensing, Vol. 37, No. 5, P. 520-528, 2011. DOI: 10.5589/m11-063.

17. van Zadelhoff, G. J.; Stoffelen, A.; Vachon, P. W.; Wolfe, J.; Horstmann, J.; Belmonte Rivas, M. Scatterometer hurricane wind speed retrievals using cross polarization. Atmos. Meas. Tech. Discuss., Vol. 7, No. 2, P. 7945-7984. DOI: $10.5194 /$ amtd-6-7945-2013.

18. Uher, J.; Bornemann, J.; Rosenberg, U. Waveguide Components for Antenna Feed Systems: Theory and CAD. Michigan University: Artech House, 1993. $457 \mathrm{p}$.

19. Rudge, A. W.; Milne, K.; Oliver, A. D.; Knight, P. The Handbook of Antenna Design. London: Short Run Press LTD, 1982, 720 p.

20. Винницкий, А.С. Автономные радиосистемы : учеб. пособие. М.: Радио и связь, 1986.336 с.

21. Сколник, М. Справочник по радиолокации Т. 3: Радиолокаиионные устройства и системы. М.: Сов. Радио, 1979. 528 с. 
22. Troitskaya, Y. I.; Sergeev, D. A.; Kandaurov, A. A.; Baidakov, G. A.; Vdovin, M. A.; Kazakov, V. I. Laboratory and theoretical modeling of air-sea momentum transfer under severe wind conditions. J. Geophys. Res., Vol. 117, No. C11, P. C00J21, 2012. DOI: 10.1029/2011 JC007778.

23. Valenzuela, G. R. Theories for the interaction of electromagnetic and oceanic waves - A review. Bounda-

Поступила в редакцию 29.11.2016
ry-Layer Meteorology, Vol. 13, No. 1-4, P. 61-85, 1978. DOI: $\underline{10.1007 / \mathrm{BF} 00913863}$.

24. Troitskaya, Yu.; Abramov, V.; Ermoshkin, A.; Zuikova, E.; Kazakov, V.; Sergeev, D.; Kandaurov, A.; Ermakova, O. Laboratory study of cross-polarized radar return under gale-force wind conditions. Int. J. Remote Sens., Vol. 37, No. 9, P. 1981-1989, 2016. DOI: 10.1080/01431161.2016.1160301.

После переработки 25.07.2017 